\title{
Maternal Childhood Trauma and Perinatal Distress Predict Infants' Attention From 6 to 18 Months
}

\author{
Hsing-Fen Tu ( $\nabla$ hsingfen@cbs.mpg.de) \\ Max Planck Institute for Human Cognitive and Brain Sciences \\ Alkistis Skalkidou \\ Uppsala University \\ Marcus Lindskog \\ Uppsala University \\ Gustaf Gredebäck \\ Uppsala University
}

\section{Research Article}

Keywords: Sustained attention, infancy, maternal anxiety, maternal childhood trauma, cross-generational effect

Posted Date: September 24th, 2021

DOI: https://doi.org/10.21203/rs.3.rs-923365/v1

License: (1) (1) This work is licensed under a Creative Commons Attribution 4.0 International License. Read Full License 
Hsing-Fen Tu*1,3, Alkistis Skalkidou ${ }^{2}$, Marcus Lindskog $^{3} \&$ Gustaf Gredebäck ${ }^{3}$

${ }^{1}$ Department of Neurology, Max Planck Institute for Human Cognitive and Brain Sciences, 04103 Leipzig, Germany. ${ }^{2}$ Department of Women's and Children's Health, Uppsala University, 75237 Uppsala, Sweden. ${ }^{3}$ Department of Psychology, 75237 Uppsala University, Uppsala, Sweden

Author Note

The work was supported by a grant from KAW 2012.0120, Knut and Alice Wallenberg

Foundation to Gredebäck, and by the Swedish Research Council (Project No. 523-2014-2342), the Swedish Society of Medicine (Project No. SLS-250581), the Marianne and Marcus Wallenberg Foundation (Project No. MMW2011.0115), and the Göran Gustafsson Foundation (1551 A) to Skalkidou. We are grateful to all the families who take part in this ongoing study project. We also thank Max Planck Institute for Human Cognitive and Brain Sciences for the collaboration. The data that support the findings of this study are available on request from the corresponding author. The authors declare that there is no known conflict of interest to disclose. Correspondence concerning this article should be addressed to Hsing-Fen Tu, Max Planck Institute for Human Cognitive and Brain Sciences, Leipzig, Germany. Email: hsingfen@cbs.mpg.de. 


\section{MATERNAL DISTRESS AND INFANTS' ATTENTION}

\section{Abstract}

Maternal distress is repeatedly reported to have negative impacts on the cognitive

3 development in children. Studies examining the association between maternal distress and the

4 development of attention in infancy are few. This study investigated the longitudinal

5 relationships between maternal distress (depressive symptoms, anxiety symptoms, and

6 exposure to childhood trauma) and the development of attention in infancy in 118 mother-infant

7 dyads. We found that maternal exposure to non-interpersonal traumatic events in childhood and

8 a large degree of anxiety during the $2^{\text {nd }}$ trimester was associated with less attention of the infants

9 to audio-visual stimuli at 6,10 , and 18 months. In addition, exposure to interpersonal traumatic

10 events in childhood was identified as a moderator of the negative effect of maternal anxiety

11 during the $2^{\text {nd }}$ trimester on the development of attention in infants. We discuss the possible

12 mechanisms accounting for these cross-generational effects. Our findings underscore the

13 importance of maternal mental health to the development of attention in infancy and address

14 the need for early screening of maternal mental health during pregnancy.

18 Keywords

19 Sustained attention, infancy, maternal anxiety, maternal childhood trauma, cross-generational 20 effect 


\section{MATERNAL DISTRESS AND INFANTS'ATTENTION}

\section{Introduction}

Attention in infancy is an important cognitive operation involving alerting, orienting, and attending to information in the environment ${ }^{1}$. Attention develops rapidly in the first postnatal year ${ }^{2}$ and continues to develop into adulthood ${ }^{3}$, playing a fundamental role in learning ${ }^{4,5}$. Attention is also linked to the development of self-regulation and executive function in childhood ${ }^{6,7}$. Attention is seen as a predictor of social development ${ }^{8}$, cognitive functioning 9 , language development ${ }^{10}$, and academic skills ${ }^{11}$. Poor attention skills are related to several neurodevelopmental disorders, such as attention-deficit/hyperactivity disorder (ADHD) ${ }^{12}$ and autism spectrum disorder $(\mathrm{ASD})^{13}$. Taken together, identifying the risk factors of the development of attention in early years is crucial for prevention and intervention.

Maternal distress is seen to influence the trajectories of attentional development in childhood. Extensive evidence from large cohort groups has shown that maternal depressive and anxiety symptoms are associated with attention problems in offspring at the ages of 2 years $^{14}, 3$ and 4 years $^{15}$, as well as $5,6.5$, and 14 years $^{16,17}$. Maternal distress is also linked to ADHD symptoms at the age of 4 and $8-9$ years ${ }^{18,19}$. Moreover, recent studies also reported that maternal childhood adverse experiences contribute to ADHD and ASD in children ${ }^{20-22}$.

In nonhuman primates, exposure to mild stress during pregnancy is related to less visual exploration and higher distractibility of offspring ${ }^{23}$. In humans, maternal stress during pregnancy has a negative impact on infants' attention shifting at the age of 18 months ${ }^{24}$. It is been shown that infants whose mothers perceived higher stress during pregnancy needed more time than others to process visual information at the age of 7.5 months and looked away from the tasks significantly more than infants whose mothers had low perceived stress during pregnancy ${ }^{25}$. Preliminary evidence also suggests that this cross-generational association between maternal distress and infant development might be linked to trauma exposure prior to pregnancy $^{26,27}$. Moreover, infants of depressed mothers have less synchronous mutual gaze with their mothers than infants of non-depressed mothers ${ }^{28}$. In turn, mutual gaze has been associated 


\section{MATERNAL DISTRESS AND INFANTS' ATTENTION}

1 with visual attention in the first postnatal year of life ${ }^{29}$. The impact of maternal distress on

2 mother-infant interactions ${ }^{30}$ and maternal sensitivity ${ }^{31}$ have been related to infants' selective 3 attention $^{32}$ and gaze-following ability ${ }^{33}$.

Maternal distress is often symptomized by an unbalanced and/or strained emotional state from pregnancy to postpartum commonly including depression and/or anxiety ${ }^{34,35}$. The severity of psychological distress is strongly linked to exposure to traumatic experiences earlier in life ${ }^{36,37}$. Evidence also suggests different types of traumatic events, such as interpersonal and non-interpersonal trauma, have different impacts on mental distress and psychiatric symptoms $^{38,39}$. Overall, the literature suggests that maternal distress is multifaceted and it contributes to the development of attention in children. However, contrary to compelling evidence indicating the impact of specific variables related to maternal psychological distress on the development of attention in childhood, there is only very little evidence investigating the impact of multiple dimensions of maternal distress on infants and following the full path from mother's childhood, pregnancy to $1^{\text {st }}$ postnatal year. The analysis of multiple risk factors together is essential due to the high likelihood of co-morbidity and high correlations between risk factors. To bridge this gap, in the current study, we took depression, anxiety, and trauma exposure into consideration. The main aim of this longitudinal study was to investigate how maternal childhood trauma and maternal distress are related to infants' attention from 6 to 18 months of age. We hypothesize that maternal childhood trauma exposure and maternal distress are negatively associated with the infant's attention. In addition, besides identifying the risk factors that might hinder infants' attention, we also preliminarily explored the supportive factors that might buffer against the negative impact of maternal distress. Methods and results are reported in the supplementary information.

\section{Results}




\section{MATERNAL DISTRESS AND INFANTS' ATTENTION}

As seen in Table 1 , Model A $\left(F(6,103)=3.698, R^{2}=0.177, p=0.02\right)$ includes all significant variables systematically selected from Table 2 as described in the Methods. We observed that higher levels of interpersonal traumatic experience in childhood interact with anxiety during the $2^{\text {nd }}$ trimester and a decrease in infants' attention (see Model $\mathrm{A}$ in Table $1, b$ $=-0.037, p=0.015)$. We also found two main effects. First, when mothers were exposed to higher levels of non-interpersonal trauma in childhood, there was a decrease in infants' attention to audio-visual stimuli $(b=-0.029, p=0.012)$. Second, when mothers reported higher levels of anxiety during the $2^{\text {nd }}$ trimester, infants increased their attention $(b=0.053, p=0.02)$. The second step, Model B $\left(F(4,105)=5.287, R^{2}=0.168, p<0.001\right)$ contained only variables that were significant predictors in Model A. All effects remained significant in Model B: the interaction between interpersonal traumatic events and anxiety level during the $2^{\text {nd }}$ trimester $(b=-0.039, p<0.001)$, the main effect of non-interpersonal traumatic events $(b=$ $0.029, p<0.05)$, and the main effect of anxiety level during the $2^{\text {nd }} \operatorname{trimester}(b=0.051, p<$ $0.01)$

After controlling for infant's sex, mother's education, smoking habits, and maternal age at birth, Model $\mathrm{C}\left(F(8,99)=2.658, R^{2}=0.177, p=0.011\right)$ showed that the interaction between interpersonal traumatic experiences and anxiety during the $2^{\text {nd }}$ trimester $(b=-0.040, p<0.001)$, the main effect of non-interpersonal traumatic events $(b=-0.029, p<0.05)$, and the anxiety level during pregnancy during $2^{\text {nd }}$ trimester $(b=0.052, p<0.01)$ all remained significant. Figure 1 visualizes the results of Model C. 
Insert Table 2.

3

4

Moderation analysis

\section{Insert Figure 1.}

Following the results described above, exposure to interpersonal traumatic events in childhood was examined as a moderator of the relationship between the anxiety level during the $2^{\text {nd }}$ trimester and the infants' look percentage after adjusting for infant sex and mother's education. Figure 2 displays the slopes for the anxiety level during antenatal 17 weeks and the levels of the exposure to interpersonal traumatic events predicting infants' attention. As indicated by the change in the direction, the effect is moderated by interpersonal traumatic events $\left(\mathrm{F}(5,103)=2.916, R^{2}=0.124, p=0.018\right)$. In other words, with a higher exposure of interpersonal traumatic events, infants' attention decreases as the mother's anxiety level increases.

\section{Discussion}

The primary goal of the current study was to investigate whether maternal distress affects the development of attention in infancy. We found that exposure to non-interpersonal and interpersonal traumatic experiences childhood has cross-generational effects on infants' attention. Moreover, childhood interpersonal trauma experience moderates the maternal anxiety 


\section{MATERNAL DISTRESS AND INFANTS' ATTENTION}

1 level during the $2^{\text {nd }}$ trimester and hinders the development of attention in infancy. In other

2 words, our results indicate that both traumatic experiences in mothers' childhood and perinatal

3 anxiety increase the vulnerability of mothers and elevate the risk for poor attention of infants.

4 From the standpoint of prevention, our findings underscore the importance of early screening

5 and intervention for mental health issues to support mothers and infants and prevent long-term

6 consequences, even before the pregnancy starts.

In our longitudinal data across pregnancy to early infancy, we found a particular vulnerability in the $2^{\text {nd }}$ trimester. There are two main possible explanations for this finding. The first explanation is that the fetal brain is vulnerable to the in-utero environment due to the critical period of neurogenesis. Exposure to risk factors during this stage of development leads to altered neuron connectivity. Compared to the $1^{\text {st }}$ and $3^{\text {rd }}$ trimesters, exposure to ethanol in the $2^{\text {nd }}$ trimester has been reported to cause great neuronal loss in rodents ${ }^{40}$, attenuated cerebral blood flow ${ }^{41}$, and long-lasting alternations in synaptic plasticity ${ }^{42}$ in the human fetus. In children, a previous study also reported that maternal anxiety during the $2^{\text {nd }}$ trimester, but not later during pregnancy, is associated with gray matter reduction in several brain areas in children (6-9 years old $)^{43}$, including the prefrontal lobe, which is a crucial area in cognitive development ${ }^{44}$ and controls attention ${ }^{45}$. The second explanation is associated with the elevated cortisol levels in mothers during pregnancy. Compared to mothers who do not experience maternal anxiety, childhood maltreatment, or an adverse environment, mothers who experience anxiety or these traumatic experiences have a higher level of cortisol ${ }^{46-48}$. Scheinost et al. reported that increased cortisol levels during the $2^{\text {nd }}$ trimester and increased subjective maternal distress in the $3^{\text {rd }}$ trimester are associated with weaker connectivity of the anterior cingulate cortex of neonates $^{49}$. The anterior cingulate cortex has been linked to infant's attention ${ }^{50,51}$ and ADHD in children ${ }^{52,53}$ and adults ${ }^{54}$. In addition, one previous study investigating infants' 


\section{MATERNAL DISTRESS AND INFANTS' ATTENTION}

1 performance were born to mothers with lower maternal cortisol levels in the $2^{\text {nd }}$ trimester but

2 higher cortisol levels in the $3^{\text {rd }}$ trimester ${ }^{55}$.

Interestingly, maternal depression showed no association with infants' attention. However, previous literature has shown that infants of depressed mothers have a less synchronous gaze in the mother-infant interaction ${ }^{28,56}$ that may affect the development of attention $^{29}$. Similar to two well-controlled studies investigating cognitive development, maternal depression during pregnancy and infancy did not affect cognitive development at the age of 3 years ${ }^{57}$ and 18 months $^{58}$, respectively. In the context of the current study, there are several plausible reasons for this finding. First, the association between maternal depression and infants' attention may not exist. However, using the same dataset investigating gaze following, infants of mothers with lower levels of postpartum depression presented better skills in synchronizing visual attention with others based on their gaze direction ${ }^{33}$. Though mutual gaze interaction can predict attention in infancy ${ }^{29}$, our data and Astor et al.'s study ${ }^{33}$ show that there may be more than one pathway of mother-infant interaction that influences the development of attention. Second, it is possible that the impact of maternal depression on infants' attention is cumulative and becomes significant only in childhood ${ }^{17}$. Third, as maternal depression is complex and heterogeneous in nature ${ }^{59-61}$, our four time points may not reflect the complexity and heterogeneity of associations across mothers and infants. Lastly, because of the rigorous nature of the BASIC study, among mothers with depressive symptoms, a higher proportion of those with high functioning/cognitive skills (of which the children might also have good attention) are hypothesized to have filled out the questionnaires, introducing a possible selection bias.

Keeping these alternatives in mind, we cautiously propose another reason. Given the high comorbidity of depression and anxiety in our data (Table 4) and the literature ${ }^{62,63}$, we propose that anxiety may be the driving force behind peripartum depression. For example, when we examined depressive and anxiety symptoms separately (Table 2), they showed a unique 


\section{MATERNAL DISTRESS AND INFANTS' ATTENTION}

1 effect during the $2^{\text {nd }}$ trimester. When we further combined all dimensions and examined the

2 effect while simultaneously controlling others, anxiety dominated the effect. To the best of our

3 knowledge, maternal depression and anxiety are rarely combined and related to child

4 development, meaning that the importance of maternal anxiety may have been interpreted as

5 an effect of depression in prior work. However, the complexity and dynamics between

6 traumatic experiences, depression, and anxiety and how the dynamics change over time are

7 beyond the scope of the current study. Future studies are needed to help us understand how

8 maternal mental health affects infants' attention. Most importantly, it will provide us more

9 knowledge on promoting maternal mental health and infant development.

Finally, and especially due to our limited sample size, our results must be interpreted in

light of some limitations. Firstly, we could not compare clinically severe cases due to the relatively small number of severely depressed mothers. To deal with the relatively small sample size and the significant collinearity between depression and anxiety, we calculated the factor scores for depression and anxiety separately at four different time points. This may prevent the plausible interactions at different stages and different levels from being observable in our results. Moreover, our sample is limited to a homogenous population in Uppsala (Sweden), with more than half of participating mothers having education levels of university or higher. In addition, we did not control for the possible influence of partners' mental health on mothers' well-being and infants' attention. As our results indicate the important influence of interpersonal traumatic experiences, future studies should consider this interpersonal aspect and its dynamics with regard to mothers' well-being.

Our findings add to the growing body of research, suggesting that prevention and intervention should start before pregnancy for both mothers and infants. Lastly, the findings describe a previously undocumented connection between maternal early trauma, anxiety, and the development of attention in infants. Treating pregnant women's anxiety, especially if she 


\section{MATERNAL DISTRESS AND INFANTS' ATTENTION}

1 has experienced traumatic events in the past, may not only improve the lives of mothers, but

2 also support positive development of their children from infancy onwards.

3

4

5

\section{Methods}

\section{Participants}

The final data included 118 mother-infant dyads from the BASICchild cohort as part of a longitudinal study (the BASIC Child Project) ${ }^{64}$ of a subsample of the population-based BASIC study "Biology, Affect, Stress, Imaging, and Cognition (BASIC)"65 collected from 2014 to 2018. Characteristics of the mother-infant dyads are shown in Table 3. Only healthy pregnant women $>18$ years old who received a routine examination at Uppsala University Hospital were invited to participate in the projects. Mothers who consented to participate were invited to fill out a series of questionnaires online at 17 and 32 gestational weeks, and postpartum at 6 weeks, 6 months, and 12 months. Mothers and infants who took part in the BASIC Child Project visited the Uppsala Child and Baby Lab when the infants were aged $6(n=118$; mean $=185$ days, SD $=7.5$ days, 59 boys $), 10(n=110$; mean $=302$ days, $\mathrm{SD}=9.2$ days, 53 boys $)$, and 18 months $(n=104 ;$ mean $=544$ days, $\mathrm{SD}=12.1$ days, 53 boys $)$. All infants were reported healthy. Sixtyfive percent of the mothers held a university degree. All procedures in the study were conducted in accordance with the 1964 Declaration of Helsinki ethical standards and approved by the Regional Ethical Review Board in Uppsala, Sweden (EPN). Mothers who agreed to participate in the online surveys returned their written informed consent prior to the study. For participating infants, all legal guardians provided written informed consent during each visit prior to the experiment. Participants received a gift voucher worth approximately 30 euros after each visit to the lab.

\section{Insert Table 3.}




\section{MATERNAL DISTRESS AND INFANTS' ATTENTION}

1

\section{Measures of maternal distress}

Symptoms of depression were measured using the Swedish version of the Edinburgh Postnatal Depression Scale (EPDS) ${ }^{66,67}$. The EPDS includes 10 questions scored from 0 to 3. Thus, the total score ranges from 0 to 30 , with higher scores indicating more severe symptoms. The reliability and validity of the EPDS has been shown to be adequate ${ }^{68,69}$. Symptoms of anxiety was measured using the Beck Anxiety Inventory (BAI $)^{70}$. The scale consists of 21 items, with participants indicating the extent to which they were bothered by each item. The total score for each item ranges from 0 to 63 , with higher scores indicating more server symptoms ${ }^{71}$. A high level of internal consistency and a good test-retest correlation have been reported ${ }^{70}$. Mothers in the study completed the online version of both EPDS and BAI at 17 and 32 weeks of pregnancy and 6 weeks and 6 months of the first postnatal year. Childhood traumatic exposure was measured using the Swedish version of the Life Incidence of Traumatic Events $(\text { LITE })^{72,73}$. The LITE is a self-reported checklist that consists of 15 fixed items and one optional item. Each item enquires whether the event has occurred, how many times, the age of the first occurrence, and how inconvenient it remains now. The first eight items ask whether different types of non-interpersonal traumatic events (nIP) have occurred, whereas the remaining items ask whether the seven types of events regarding interpersonal traumatic events (IP) occurred. Interpersonal events are defined as events dependent on a conscious act of another human being, such as physical harm, divorce, or separation of parents, etc. Noninterpersonal events include natural disasters, accidents, or illness of others, etc. The sums of occurrences of nIP and IP were used as two variables in the analysis. Acceptable test-retest reliability and validity have been reported ${ }^{74}$. Mothers in the current study were invited to complete the LITE online during postpartum 12 months. 


\section{MATERNAL DISTRESS AND INFANTS' ATTENTION}

Infants' attention was measured by the look percentage (defined as the total fixation duration of the stimuli divided by the total duration of all tasks at each age) across a variety of free-looking tasks at the age of 6,10 , and 18 months. Attention is assumed to be closely linked to oculomotor movement and oculomotor control ${ }^{75,76}$ and, in this study, look percentage is used as a proxy for sustained attention ${ }^{77,78}$. The mean look percentage at 6,10 , and 18 months was $73.63 \%(\mathrm{SD}=9.84), 73.47 \%(\mathrm{SD}=9.36)$, and 79.24\% $(\mathrm{SD}=6.86)$, respectively. The Pearson correlation coefficients (Table 4) of attention, look percentage, between different ages were 0.33 (6-10 months, $n=110, p<0.001), 0.21$ (6-18 months, $n=103, p=0.04)$, and $0.31(10-$ 18 months, $n=100, p<0.01)$, suggesting the stability and internal consistency of attention during the course of development. In the current study, the composite score of look percentage was calculated by averaging each participant's look percentage measured at three time points and used as the dependent variable. All tasks were recorded using an eye-tracker with a sampling rate of $60 \mathrm{~Hz}$ following a 5-point calibration (Tobii TX300, Tobii Technology AB, Sweden).

Insert Table 4.

\section{Statistical analysis}

We used multivariate linear regression models and a moderator analysis to examine the association between multiple predictors across different time points and the outcome measure. To assess the reliability of the maternal scale instruments, we calculated the internal consistency coefficient, Cronbach's alpha for each tool: EPDS, 0.87, good; BAI, 0.81, good; and LITE, 0.9, excellent. Before adjusting their scores, the zero-order Pearson correlations (with BenjaminiHochberg correction), skewness, and kurtosis of all variables were calculated (Table 4). The variance inflation factor (VIF) was calculated based on the assumption that infants' look 


\section{MATERNAL DISTRESS AND INFANTS' ATTENTION}

1 percentage is predicted by 10 variables from the EPDS (4 time points), BAI (4 time points),

2 and LITE (1 time point). As seen in Table 4, raw scores for anxiety symptoms during antenatal

317 weeks and postpartum 6 weeks are not in the acceptable range of the kurtosis index. The

4 raw scores of the EPDS, BAI, and LITE did not reach the range of approximate symmetric

5 distribution (kurtosis index acceptable range, -2 to +2 ; skewness index accetable range -0.5 to

$6+0.5)^{79}$. In addition, the literature has shown that comorbidity of depression and anxiety is

7 common $^{62,63}$, so we expected to detect a potential multicollinearity from the raw data. As seen

8 in Table 4, the raw scores of the EPDS and the BAI during antenatal 17 weeks fit the strict

9 criteria for multicollinearity (VIF1 $>4$ ) with other variables ${ }^{80,81}$. Considering non-normal 10 distribution and multicollinearity of the EPDS and BAI, the Kaiser-Meyer-Olkin test was used 11 to examine the sampling adequacy (MSA) and transformed all raw scores from four time points into factor scores $(\mathrm{MSA}>0.65)^{82}$. Missing values were imputed using predictive mean matching ${ }^{83}$. Individual factor scores of the EPDS and BAI at four time points were calculated

using the imputed values. The LITE raw scores, including IP and nIP, were the frequency of the occurrences. They were transformed into dichotomic variables based on the median of the raw scores in order to interpret the interaction. The outcome measure was infants' look percentage composite.

\section{Variable elimination and model fitting}

Initially, there was a theoretical selection of 10 predictors included in the current data set that evaluated trauma exposure ( 1 time point of previous IP and nIP), depressive symptoms (4 time points), and anxiety symptoms (4 time points) in the main analysis to predict infants' look percentage. No other variables except those listed here have been evaluated as part of the analysis. In step 1, considering that maternal trauma exposure prior to pregnancy (both IP and nIP) may interact with depression or anxiety, we separated variables into four groups as listed in Table 2 and analyzed four linear regression models independently. Applying a backward 


\section{MATERNAL DISTRESS AND INFANTS'ATTENTION}

1 stepwise method, the number of variables in each model was reduced ( $3^{\text {rd }}$ column, Table 2$)$. In

2 step 2, based on the statistical selection shown in Table 2, we combined the significant variables

3 and 2-degree interaction from all models to assess how they jointly predict infants' attention

4 (measured by look percentage; see Model A, Table 1). Based on Model A, we selected

5 significant variables for Model B (see Table 1). In the third step, we added the sex of infants ${ }^{84,85}$,

6 mothers' smoking habits ${ }^{86}$, education ${ }^{87}$, and the maternal age at birth $^{88}$ to the analysis (Model

7 C, Table 1). All tests were two-sided tests with $p<0.05$ considered significant. All statistical 8 analyses were performed using R 4.0.3 $3^{89}$. 


\section{References}

1 Petersen, S. E. \& Posner, M. I. The attention system of the human brain: 20 years after. Annual review of neuroscience 35, 73-89 (2012).

2 Xie, W., Mallin, B. M. \& Richards, J. E. Development of brain functional connectivity and its relation to infant sustained attention in the first year of life. Developmental Science 22, e12703 (2019).

3 Hoyer, R. S., Elshafei, H., Hemmerlin, J., Bouet, R. \& Bidet-Caulet, A. Why are children so distractible? Development of attention and motor control from childhood to adulthood. Child development (2021).

4 Johnson, M. H., Posner, M. I. \& Rothbart, M. K. Components of visual orienting in early infancy: Contingency learning, anticipatory looking, and disengaging. Journal of cognitive neuroscience 3, 335-344 (1991).

5 Holland, P. C. \& Maddux, J.-M. Brain systems of attention in associative learning. Attention and learning, 305-349 (2010).

6 Posner, M. I. \& Rothbart, M. K. Toward a physical basis of attention and selfregulation. Physics of life reviews 6, 103-120 (2009).

7 Cuevas, K. \& Bell, M. A. Infant attention and early childhood executive function. Child Development 85, 397-404 (2014).

8 Bowers, K. et al. Early infant attention as a predictor of social and communicative behavior in childhood. International Journal of Behavioral Development 43, 204-211 (2019).

9 Lawson, K. \& Ruff, H. Early attention and negative emotionality predict later cognitive and behavioural function. International Journal of Behavioral Development 28, 157-165 (2004).

10 Yu, C., Suanda, S. H. \& Smith, L. B. Infant sustained attention but not joint attention to objects at 9 months predicts vocabulary at 12 and 15 months. Developmental science 22, e12735 (2019).

11 Shannon, K. A., Scerif, G. \& Raver, C. C. Using a multidimensional model of attention to predict low-income preschoolers' early academic skills across time. Developmental science 24, e13025 (2021).

12 Barkley, R. A. Behavioral inhibition, sustained attention, and executive functions: constructing a unifying theory of ADHD. Psychological bulletin 121, 65 (1997).

13 Matson, J. L., Rieske, R. D. \& Williams, L. W. The relationship between autism spectrum disorders and attention-deficit/hyperactivity disorder: An overview. Research in developmental Disabilities 34, 2475-2484 (2013).

14 Ross, K. M., Letourneau, N., Climie, E., Giesbrecht, G. \& Dewey, D. Perinatal Maternal Anxiety and Depressive Symptoms and Child Executive Function and Attention at Two-years of Age. Developmental Neuropsychology 45, 380-395 (2020).

15 Van Batenburg-Eddes, T. et al. Parental depressive and anxiety symptoms during pregnancy and attention problems in children: a cross-cohort consistency study. Journal of Child Psychology and Psychiatry 54, 591-600 (2013).

16 Clavarino, A. M. et al. Maternal anxiety and attention problems in children at 5 and 14 years. Journal of attention disorders 13, 658-667 (2010).

17 Wang, Y. \& Dix, T. Mothers' depressive symptoms in infancy and children's adjustment in grade school: The role of children's sustained attention and executive function. Developmental psychology 53, 1666 (2017).

18 Vizzini, L. et al. Maternal anxiety, depression and sleep disorders before and during pregnancy, and preschool ADHD symptoms in the NINFEA birth cohort study. Epidemiology and psychiatric sciences 28, 521-531 (2019). 
19 Mulraney, M. et al. Maternal postnatal mental health and offspring symptoms of ADHD at 8-9 years: pathways via parenting behavior. European child \& adolescent psychiatry 28, 923-932 (2019).

20 Roberts, A. L., Liew, Z., Lyall, K., Ascherio, A. \& Weisskopf, M. G. Association of maternal exposure to childhood abuse with elevated risk for attention deficit hyperactivity disorder in offspring. American journal of epidemiology 187, 1896-1906 (2018).

21 Moon, D.-S., Bong, S.-J., Kim, B.-N. \& Kang, N. R. Association between Maternal Adverse Childhood Experiences and Attention-Deficit/Hyperactivity Disorder in the Offspring: The Mediating Role of Antepartum Health Risks. Journal of the Korean Academy of Child and Adolescent Psychiatry 32, 28 (2021).

22 Roberts, A. L., Lyall, K., Rich-Edwards, J. W., Ascherio, A. \& Weisskopf, M. G. Association of maternal exposure to childhood abuse with elevated risk for autism in offspring. JAMA psychiatry 70, 508-515 (2013).

23 Schneider, M. L. The effect of mild stress during pregnancy on birthweight and neuromotor maturation in rhesus monkey infants (Macaca mulatta). Infant Behavior and Development 15, 389-403 (1992).

24 Plamondon, A. et al. Spatial working memory and attention skills are predicted by maternal stress during pregnancy. Early Human Development 91, 23-29 (2015).

25 Merced-Nieves, F. M., Dzwilewski, K. L., Aguiar, A., Lin, J. \& Schantz, S. L. Associations of prenatal maternal stress with measures of cognition in 7.5-month-old infants. Developmental psychobiology (2020).

26 Bosquet Enlow, M. et al. Maternal lifetime trauma exposure, prenatal cortisol, and infant negative affectivity. Infancy 22, 492-513 (2017).

27 Bouvette-Turcot, A.-A. et al. Maternal symptoms of depression and sensitivity mediate the relation between maternal history of early adversity and her child temperament: the inheritance of circumstance. Development and psychopathology 32, 605-613 (2020).

28 Lotzin, A. et al. Gaze synchrony between mothers with mood disorders and their infants: maternal emotion dysregulation matters. PLoS one 10, e0144417 (2015).

29 Niedźwiecka, A., Ramotowska, S. \& Tomalski, P. Mutual gaze during early motherinfant interactions promotes attention control development. Child Development 89, 2230-2244 (2018).

30 Granat, A., Gadassi, R., Gilboa-Schechtman, E. \& Feldman, R. Maternal depression and anxiety, social synchrony, and infant regulation of negative and positive emotions. Emotion 17, 11 (2017).

31 Bernard, K., Nissim, G., Vaccaro, S., Harris, J. L. \& Lindhiem, O. Association between maternal depression and maternal sensitivity from birth to 12 months: a metaanalysis. Attachment \& human development 20, 578-599 (2018).

32 Juvrud, J., Haas, S. A., Fox, N. A. \& Gredebäck, G. Infants' Selective Visual Attention Is Dependent on Maternal Affect and Emotional Context. Frontiers in Psychology 12, doi:10.3389/fpsyg.2021.700272 (2021).

33 Astor, K. et al. Social and emotional contexts predict the development of gaze following in early infancy. Royal Society open science 7, 201178 (2020).

34 Fontein-Kuipers, Y. Maternal Distress-Every Unhappy Pregnant Woman is Unhappy in Her Own Way. J Psychiatry Ment Health 1 (2016).

35 Priest, S., Austin, M.-P., Barnett, B. \& Buist, A. A psychosocial risk assessment model (PRAM) for use with pregnant and postpartum women in primary care settings. Archives of women's mental health 11, 307-317 (2008).

36 Chu, D. A., Williams, L. M., Harris, A. W., Bryant, R. A. \& Gatt, J. M. Early life trauma predicts self-reported levels of depressive and anxiety symptoms in nonclinical 
community adults: Relative contributions of early life stressor types and adult trauma exposure. Journal of psychiatric research 47, 23-32 (2013).

37 Sexton, M. B., Hamilton, L., McGinnis, E. W., Rosenblum, K. L. \& Muzik, M. The roles of resilience and childhood trauma history: main and moderating effects on postpartum maternal mental health and functioning. Journal of affective disorders 174, 562-568 (2015).

38 Haldane, J. \& Nickerson, A. The impact of interpersonal and noninterpersonal trauma on psychological symptoms in refugees: The moderating role of gender and trauma type. Journal of Traumatic Stress 29, 457-465 (2016).

39 Baker, D. E. et al. Interpersonal vs. non-interpersonal cumulative traumas and psychiatric symptoms in treatment-seeking incarcerated women. Journal of Trauma \& Dissociation, 1-16 (2020).

40 Miller, M. W. \& Potempa, G. Numbers of neurons and glia in mature rat somatosensory cortex: effects of prenatal exposure to ethanol. Journal of Comparative Neurology 293, 92-102 (1990).

41 Mayock, D. E., Ness, D., Mondares, R. L. \& Gleason, C. A. Binge alcohol exposure in the second trimester attenuates fetal cerebral blood flow response to hypoxia. Journal of applied physiology 102, 972-977 (2007).

42 Helfer, J. L., White, E. R. \& Christie, B. R. Enhanced deficits in long-term potentiation in the adult dentate gyrus with 2 nd trimester ethanol consumption. PloS one 7, e51344 (2012).

43 Buss, C., Davis, E. P., Muftuler, L. T., Head, K. \& Sandman, C. A. High pregnancy anxiety during mid-gestation is associated with decreased gray matter density in 6-9year-old children. Psychoneuroendocrinology 35, 141-153 (2010).

44 Casey, B., Tottenham, N., Liston, C. \& Durston, S. Imaging the developing brain: what have we learned about cognitive development? Trends in cognitive sciences $\mathbf{9}$, 104-110 (2005).

45 Paneri, S. \& Gregoriou, G. G. Top-down control of visual attention by the prefrontal cortex. Functional specialization and long-range interactions. Frontiers in neuroscience 11, 545 (2017).

46 Bowers, K. et al. Maternal distress and hair cortisol in pregnancy among women with elevated adverse childhood experiences. Psychoneuroendocrinology 95, 145-148 (2018).

47 Stephens, J. E. et al. Early and current life adversity: Past and present influences on maternal diurnal cortisol rhythms during pregnancy. Developmental Psychobiology 63, 305-319 (2021).

48 Leff-Gelman, P. et al. Cortisol and DHEA-S levels in pregnant women with severe anxiety. BMC psychiatry 20, 1-14 (2020).

49 Scheinost, D., Spann, M. N., McDonough, L., Peterson, B. S. \& Monk, C. Associations between different dimensions of prenatal distress, neonatal hippocampal connectivity, and infant memory. Neuropsychopharmacology, 1-8 (2020).

50 Reynolds, G. D., Courage, M. L. \& Richards, J. E. Infant attention and visual preferences: Converging evidence from behavior, event-related potentials, and cortical source localization. Developmental Psychology 46, 886 (2010).

51 Reynolds, G. D. \& Richards, J. E. Familiarization, attention, and recognition memory in infancy: an event-related potential and cortical source localization study. Developmental psychology 41, 598 (2005).

52 Kelly, A. C. et al. Development of anterior cingulate functional connectivity from late childhood to early adulthood. Cerebral cortex 19, 640-657 (2009).

53 Qiu, M.-g. et al. Changes of brain structure and function in ADHD children. Brain topography 24, 243-252 (2011). 
54 Seidman, L. J. et al. Dorsolateral prefrontal and anterior cingulate cortex volumetric abnormalities in adults with attention-deficit/hyperactivity disorder identified by magnetic resonance imaging. Biological psychiatry 60, 1071-1080 (2006).

55 Davis, E. P. \& Sandman, C. A. The timing of prenatal exposure to maternal cortisol and psychosocial stress is associated with human infant cognitive development. Child development 81, 131-148 (2010).

56 Væver, M. S., Krogh, M. T., Smith-Nielsen, J., Christensen, T. T. \& Tharner, A. Infants of depressed mothers show reduced gaze activity during mother-infant interaction at 4 months. Infancy 20, 445-454 (2015).

57 Tse, A. C., Rich-Edwards, J. W., Rifas-Shiman, S. L., Gillman, M. W. \& Oken, E. Association of maternal prenatal depressive symptoms with child cognition at age 3 years. Paediatric and perinatal epidemiology 24, 232-240 (2010).

58 Piteo, A. M., Yelland, L. N. \& Makrides, M. Does maternal depression predict developmental outcome in 18 month old infants? Early human development 88, 651655 (2012).

59 Santos, H., Tan, X. \& Salomon, R. Heterogeneity in perinatal depression: how far have we come? A systematic review. Archives of women's mental health 20, 11-23 (2017).

60 Wikman, A. et al. Characteristics of women with different perinatal depression trajectories. Journal of neuroscience research 98, 1268-1282 (2020).

61 Mughal, M. K. et al. Trajectories of maternal stress and anxiety from pregnancy to three years and child development at 3 years of age: Findings from the All Our Families (AOF) pregnancy cohort. Journal of affective disorders 234, 318-326 (2018).

62 Dipietro, J. A., Costigan, K. A. \& Sipsma, H. L. Continuity in self-report measures of maternal anxiety, stress, and depressive symptoms from pregnancy through two years postpartum. Journal of Psychosomatic Obstetrics \& Gynecology 29, 115-124 (2008).

63 Hirschfeld, R. M. The comorbidity of major depression and anxiety disorders: recognition and management in primary care. Primary care companion to the Journal of clinical psychiatry 3, 244 (2001).

64 Gredebäck, G., Forssman, L., Lindskog, M. \& Kenward, B. The BasicChild Project. (2019).

65 Axfors, C. et al. Cohort profile: the Biology, Affect, Stress, Imaging and Cognition (BASIC) study on perinatal depression in a population-based Swedish cohort. BMJ open 9, e031514 (2019).

66 Cox, J. L., Holden, J. M. \& Sagovsky, R. Detection of postnatal depression: development of the 10-item Edinburgh Postnatal Depression Scale. The British journal of psychiatry 150, 782-786 (1987).

67 Wickberg, B. \& Hwang, C. The Edinburgh postnatal depression scale: validation on a Swedish community sample. Acta Psychiatrica Scandinavica 94, 181-184 (1996).

68 Affonso, D. D., De, A. K., Horowitz, J. A. \& Mayberry, L. J. An international study exploring levels of postpartum depressive symptomatology. Journal of psychosomatic research 49, 207-216 (2000).

69 Cox, J. L., Chapman, G., Murray, D. \& Jones, P. Validation of the Edinburgh Postnatal Depression Scale (EPDS) in non-postnatal women. Journal of affective disorders 39, 185-189 (1996).

70 Beck, A. T., Epstein, N., Brown, G. \& Steer, R. A. An inventory for measuring clinical anxiety: psychometric properties. Journal of consulting and clinical psychology 56, 893 (1988).

71 Beck, A. T. \& Steer, R. A. Beck anxiety inventory: BAI. (Psychological Corporation, 1993). 
72 Greenwald, R. \& Rubin, A. Assessment of posttraumatic symptoms in children: Development and preliminary validation of parent and child scales. Research on Social Work Practice 9, 61-75 (1999).

73 Larsson, I. LITE-P, life incidence of traumatic events. Translation into Swedish, with permission from the author In: R Greenwald (2003).

74 Nilsson, D., Gustafsson, P. E. \& Svedin, C. G. Self-reported potentially traumatic life events and symptoms of post-traumatic stress and dissociation. Nordic journal of psychiatry 64, 19-26 (2010).

75 Amso, D. \& Scerif, G. The attentive brain: insights from developmental cognitive neuroscience. Nature Reviews Neuroscience 16, 606-619 (2015).

76 Corbetta, M. et al. A common network of functional areas for attention and eye movements. Neuron 21, 761-773 (1998).

77 Casey, B. \& Richards, J. E. Sustained visual attention in young infants measured with an adapted version of the visual preference paradigm. Child Development, 1514-1521 (1988).

78 Richards, J. E. \& Turner, E. D. Extended visual fixation and distractibility in children from six to twenty-four months of age. Child Development 72, 963-972 (2001).

79 Kline, R. B. Principles and practice of structural equation modeling. (Guilford publications, 2015).

80 Pan, Y. \& Jackson, R. T. Ethnic difference in the relationship between acute inflammation and serum ferritin in US adult males. Epidemiology \& Infection 136, 421-431 (2008).

81 Rogerson, P. A. Statistical methods for geography: a student's guide. (Sage, 2019).

82 Kaiser, H. F. An index of factorial simplicity. Psychometrika 39, 31-36 (1974).

83 Wulff, J. N. \& Jeppesen, L. E. Multiple imputation by chained equations in praxis: guidelines and review. Electronic Journal of Business Research Methods 15, 41-56 (2017).

84 Arnett, A. B., Pennington, B. F., Willcutt, E. G., DeFries, J. C. \& Olson, R. K. Sex differences in ADHD symptom severity. Journal of Child Psychology and Psychiatry 56, 632-639 (2015).

85 Friedman, S., Bruno, L. A. \& Vietze, P. Newborn habituation to visual stimuli: A sex difference in novelty detection. Journal of Experimental Child Psychology 18, 242251 (1974).

86 Linnet, K. M. et al. Maternal lifestyle factors in pregnancy risk of attention deficit hyperactivity disorder and associated behaviors: review of the current evidence. American Journal of Psychiatry 160, 1028-1040 (2003).

87 Clearfield, M. W. \& Jedd, K. E. The effects of socio-economic status on infant attention. Infant and Child Development 22, 53-67 (2013).

88 Goisis, A., Schneider, D. C. \& Myrskylä, M. The reversing association between advanced maternal age and child cognitive ability: evidence from three UK birth cohorts. International journal of epidemiology 46, 850-859 (2017).

89 Team, R. C. A language and environment for statistical computing. v3. 6.3. R Foundation for Statistical Computing, Vienna, Austria, Available Https. Www. RProject. Org/. Access 2019 (2020). 


\section{MATERNAL DISTRESS AND INFANTS’ ATTENTION}

1 Table 1. The final multivariate linear model predicting infants' look percentage

2

\begin{tabular}{llrrrll}
\hline Model & Variables & Beta & $\begin{array}{c}\text { Std. } \\
\text { Error }\end{array}$ & t value & $\boldsymbol{p}$ value & Model summary \\
\hline A & (Constant) & 0.805 & 0.022 & 36.522 & $<0.001$ & $\mathrm{~F}(6,103)=3.698$, \\
& nIP & -0.029 & 0.011 & -2.571 & 0.012 & $p=0.002, R^{2} 0.177$ \\
& BAI w17 & 0.053 & 0.023 & 2.361 & 0.020 & \\
EPDS w17 & -0.006 & 0.023 & -0.284 & 0.777 & \\
IP & -0.004 & 0.011 & -0.383 & 0.702 & \\
IP*EPDS w17 & -0.001 & 0.015 & -0.079 & 0.937 & \\
& IP*BAI w17 & -0.037 & 0.015 & -2.483 & 0.015 & \\
& & & & & \\
B & 0.804 & 0.022 & 36.662 & $<0.001$ & $\mathrm{~F}(4,105)=5.287$, \\
& (Constant) & -0.029 & 0.011 & -2.599 & 0.011 & $p<0.001, R^{2} 0.168$ \\
& nIP & -0.004 & 0.011 & -0.378 & 0.706 & \\
IP & 0.051 & 0.018 & 2.874 & 0.005 & \\
BAI w17 & -0.039 & 0.011 & -3.534 & $<0.001$ & \\
IP*BAI w17 & & & & & \\
& & 0.820 & 0.055 & 14.791 & $<0.001$ & $\mathrm{~F}(8,99)=2.658$, \\
& (Constant) & -0.029 & 0.012 & -2.495 & 0.014 & $p=0.011, R^{2} 0.177$ \\
nIP & -0.002 & 0.012 & -0.152 & 0.880 & \\
IP & 0.052 & 0.018 & 2.833 & 0.006 & \\
BAI w17 & -0.040 & 0.011 & -3.572 & $<0.001$ & \\
IP*BAI w17 & 0.001 & 0.012 & 0.50 & 0.961 & \\
Infant's sex & 0.022 & 0.014 & 01.588 & 0.115 & \\
Mother's education & 0.004 & 0.013 & 0.274 & 0.785 & \\
Mother's smoking habit & -0.002 & 0.002 & -1.300 & 0.197 & \\
Mother's age at birth & &
\end{tabular}

Model A includes all significant variables united from Table 7. Model B uses the backward stepwise method to eliminate variables and improve the model. Model $C$ is the final model after adjusting for infant sex, mother's education, smoking habit, and the mother's age birth. Abbreviations: EPDS, Edinburgh Postnatal Depression Scale; BAI, Beck Anxiety Inventory; LITE, Lifetime Incidence of Traumatic Events; $w 17$, pregnancy week 17; w32, pregnancy week 32; pv6, postpartum 6 weeks; pm6, postpartum 6 months; IP, interpersonal events; nIP, non- 
Table 2. Four separate multivariable linear regression models for systematically selecting variables for the final model

\begin{tabular}{|c|c|c|c|c|c|c|c|c|}
\hline Model & $\begin{array}{c}\text { Initial included } \\
\text { independent variables }\end{array}$ & $\begin{array}{c}\text { Independent variables after } \\
\text { backward stepwise } \\
\text { elimination }\end{array}$ & Beta & $\begin{array}{c}\text { Std. } \\
\text { Error }\end{array}$ & $\begin{array}{l}\text { Std. } \\
\text { Beta }\end{array}$ & t value & $p$ value & Model summary \\
\hline $\begin{array}{l}\text { Non-interpersonal } \\
\text { traumatic events } \\
\text { and depression }\end{array}$ & $\begin{array}{l}\text { nIP, EPDS w17, EPSD w32, } \\
\text { EPDS pw6, EPDS pm6, } \\
\text { nIP*EPDS w17, nIP*EPSD } \\
\text { w32, nIP*EPDS pw6, } \\
\text { nIP*EPDS pm6 }\end{array}$ & $\begin{array}{l}\text { (Constant) } \\
\text { nIP } \\
\text { EPDS w17 } \\
\text { EPDS pm6 }\end{array}$ & $\begin{array}{r}0.795 \\
-0.029 \\
-0.012 \\
0.006\end{array}$ & $\begin{array}{l}0.018 \\
0.012 \\
0.006 \\
0.006\end{array}$ & $\begin{array}{r}-0.233 \\
-0.199 \\
0.098\end{array}$ & $\begin{array}{r}44.636 \\
-2.507 \\
-2.145 \\
1.053\end{array}$ & $\begin{array}{l}<0.001 \\
0.014 \\
0.034 \\
0.295\end{array}$ & $\begin{array}{l}F(3,106)=3.602 \\
p=0.015, R^{2}=0.0925\end{array}$ \\
\hline $\begin{array}{l}\text { Interpersonal } \\
\text { traumatic events } \\
\text { and depression }\end{array}$ & $\begin{array}{l}\text { IP, EPDS w17, EPSD w32, } \\
\text { EPDS pw6, EPDS pm6, } \\
\text { IP*EPDS w17, IP*EPSD } \\
\text { w32, IP*EPDS pw6, } \\
\text { IP*EPDS pm6 }\end{array}$ & $\begin{array}{l}\text { (Constant) } \\
\text { EPDS w17 } \\
\text { IP*EPDS w17 }\end{array}$ & $\begin{array}{r}0.754 \\
0.026 \\
-0.025\end{array}$ & $\begin{array}{l}0.006 \\
0.019 \\
0.012\end{array}$ & $\begin{array}{r}0.422 \\
-0.634\end{array}$ & $\begin{array}{r}130.371 \\
1.415 \\
-2.125\end{array}$ & $\begin{array}{l}<0.001 \\
0.160 \\
0.036\end{array}$ & $\begin{array}{l}F(3,106)=2.936 \\
p=0.037, R^{2}=0.076\end{array}$ \\
\hline $\begin{array}{l}\text { Non-interpersonal } \\
\text { traumatic events } \\
\text { and anxiety }\end{array}$ & $\begin{array}{l}\text { nIP, BAI w17, BAI w32, } \\
\text { BAI pw6, BAI pm6, } \\
\text { nIP*BAI w17, nIP*EPSD } \\
\text { w32, nIP*BAI pw6, } \\
\text { nIP*BAI pm6 }\end{array}$ & $\begin{array}{l}\text { (Constant) } \\
\text { nIP } \\
\text { BAI w17 } \\
\text { BAI pm6 }\end{array}$ & $\begin{array}{r}0.794 \\
-0.028 \\
-0.009 \\
0.006\end{array}$ & $\begin{array}{l}0.018 \\
0.012 \\
0.006 \\
0.006\end{array}$ & $\begin{array}{r}-0.229 \\
-0.147 \\
0.098\end{array}$ & $\begin{array}{r}44.241 \\
-2.445 \\
-1.563 \\
1.046\end{array}$ & $\begin{array}{l}<0.001 \\
0.016 \\
0.121 \\
0.298\end{array}$ & $\begin{array}{l}F(3,106)=2.936 \\
p=0.037, R^{2}=0.077\end{array}$ \\
\hline $\begin{array}{l}\text { Interpersonal } \\
\text { traumatic events } \\
\text { and anxiety }\end{array}$ & $\begin{array}{l}\text { IP, BAI w17, BAI w32, BAI } \\
\text { pw6, BAI pm6, IP*BAI w17, } \\
\text { IP*EPSD w32, IP*BAI pw6, } \\
\text { IP*BAI pm6 }\end{array}$ & $\begin{array}{l}\text { (Constant) } \\
\text { BAI w17 } \\
\text { BAI pw6 } \\
\text { IP*BAI w17 }\end{array}$ & $\begin{array}{r}0.756 \\
0.051 \\
-0.008 \\
-0.039\end{array}$ & $\begin{array}{l}0.006 \\
0.018 \\
0.005 \\
0.011\end{array}$ & $\begin{array}{r}0.829 \\
-0.136 \\
-1.001\end{array}$ & $\begin{array}{r}132.995 \\
2.812 \\
-1.496 \\
-3.396\end{array}$ & $\begin{array}{l}<0.001 \\
0.006 \\
0.181 \\
0.001\end{array}$ & $\begin{array}{l}F(4,105)=3.906 \\
p=0.005, R^{2}=0.130\end{array}$ \\
\hline
\end{tabular}

Look percentage is the common dependent variable in all four models. Significant variables of each model are included in the united model.
Abbreviations: EPDS, Edinburgh Postnatal Depression Scale; BAI, Beck Anxiety Inventory; LITE, Lifetime Incidence of Traumatic Events; w17, antenatal 17 weeks; w32, antenatal 32 weeks; pv6, postpartum 6 weeks; pm6, postpartum 6 months; IP, interpersonal traumatic events; $n I P$, non-interpersonal traumatic events. 


\section{MATERNAL DISTRESS AND INFANTS' ATTENTION}

2

3

4

5

6

7

8

9

10

11

12

13

14

15

16

17

18

19

20

21

22

23

24

25

26

Table 3. Demographic characteristics of 118 mother-infant dyads

\begin{tabular}{lc}
\hline Characteristic & $\begin{array}{c}\text { Mother-infant dyad } \\
(\mathbf{n}=\mathbf{1 1 8})\end{array}$ \\
\cline { 2 - 2 } Maternal age, years & $30.54(3.92)$ \\
Country of origin & \\
$\quad$ Scandinavian & $93.1 \%$ \\
$\quad$ Other & $6.9 \%$ \\
Maternal education & \\
$\quad$ University or higher & $65.0 \%$ \\
$\quad$ Other & $35.0 \%$ \\
Cohabitating with the second caregiver & $99.2 \%$ \\
With smoking history & $36.4 \%$ \\
Employment & \\
$\quad$ Full-time & $61.2 \%$ \\
$\quad$ Part-time & $18.1 \%$ \\
$\quad$ Student & $9.5 \%$ \\
Sick leave & $4.3 \%$ \\
$\quad$ Unemployed & $6.9 \%$ \\
Length of gestation, days & $280(8.09)$ \\
Infant sex, female & $59 \%$ \\
Infant birth weight, $g$ & $3,664(481)$ \\
Infant's Apgar score at 5 minutes & \\
7 & $0.9 \%$ \\
8 & $2.6 \%$ \\
9 & $6.0 \%$ \\
10 & $90.6 \%$ \\
\hline Data are given as the proportion of dyads or mean (SD). &
\end{tabular}

4

( 
Table 4. Pe arson's zero order correlations between all variables using raw scores

\begin{tabular}{|c|c|c|c|c|c|c|c|c|c|c|c|c|c|c|c|}
\hline & $\begin{array}{l}\text { Timing of } \\
\text { measure }\end{array}$ & 1. & 2. & 3. & 4. & 5. & 6. & 7. & 8. & 9. & 10. & 11. & 12. & 13. & 14. \\
\hline 1.LP (6 months) & Postpartum & - & & & & & & & & & & & & & \\
\hline 2.LP (10 months) & Postpartum & $0.33^{* * *}$ & - & & & & & & & & & & & & \\
\hline 3. LP (18 months) & Postpartum & $0.21^{*}$ & $0.31^{* *}$ & - & & & & & & & & & & & \\
\hline 4.LP composite & Postpartum & $0.76^{* * *}$ & $0.79^{* * *}$ & $0.62^{* * *}$ & - & & & & & & & & & & \\
\hline 5.EPDS w17 & Antenatal & - & - & - & - & - & & & & & & & & & \\
\hline 6.EPDS w32 & Antenatal & - & - & - & - & $0.75^{* * *}$ & - & & & & & & & & \\
\hline 7.EPDS pw6 & Postpartum & - & - & - & - & $0.47^{* * *}$ & $0.58^{* * *}$ & - & & & & & & & \\
\hline 8.EPDS pm6 & Postpartum & - & - & - & - & $0.54^{* * *}$ & $0.57^{* * *}$ & $0.63^{* * *}$ & - & & & & & & \\
\hline 9. BAI w17 & Antenatal & - & - & - & - & $0.74^{* * *}$ & $0.60^{* * *}$ & $0.40^{* * *}$ & $0.37 * * *$ & - & & & & & \\
\hline 10.BAI w32 & Antenatal & - & - & - & - & $0.57^{* * *}$ & $0.68^{* * *}$ & $0.41^{* * *}$ & $0.41^{* * *}$ & $0.76^{* * *}$ & - & & & & \\
\hline 11.BAI pw6 & Postpartum & - & - & - & - & $0.43^{* * *}$ & $0.49^{* * *}$ & $0.62^{* * *}$ & $0.54^{* * *}$ & $0.53^{* * *}$ & $0.54^{* * *}$ & - & & & \\
\hline 12.BAI pm6 & Postpartum & - & - & - & - & $0.37^{* * *}$ & $0.49^{* * *}$ & $0.40^{* * *}$ & $0.59^{* * *}$ & $0.52^{* * *}$ & $0.53^{* * *}$ & $0.66^{* * *}$ & - & & \\
\hline 13.LITE IP & Postpartum & - & - & - & - & $0.22^{*}$ & $0.24^{*}$ & $0.25^{* *}$ & $0.25^{*}$ & $0.21^{*}$ & $0.19^{*}$ & $0.34^{* * *}$ & - & - & \\
\hline 14.LITE nIP & Postpartum & - & $-0.17^{+}$ & $-0.35^{* * *}$ & $-0.26^{* *}$ & - & - & - & - & - & - & - & - & $0.34^{* * *}$ & - \\
\hline Skewness & - & -0.87 & -0.52 & -0.85 & -0.47 & 0.95 & 0.97 & 0.79 & 0.95 & 1.47 & 1.06 & 1.45 & 1.57 & 0.95 & 0.97 \\
\hline Kurtosis & - & $1-52$ & -0.16 & 1.09 & -0.03 & 0.68 & 1.33 & 0.01 & 0.88 & 2.46 & 1.12 & 1.90 & 2.40 & 0.68 & 1.33 \\
\hline VIF 1 & - & NA & NA & NA & NA & 5.24 & 3.95 & 2.50 & 2.86 & 4.23 & 2.83 & 2.78 & 2.98 & 1.24 & 1.23 \\
\hline VIF 2 & - & NA & NA & NA & NA & 2.05 & 1.43 & 1.40 & 1.54 & 2.01 & 1.47 & 1.50 & 1.50 & 1.13 & 1.07 \\
\hline MSA & - & NA & NA & NA & NA & 0.70 & 0.71 & 0.76 & 0.77 & 0.72 & 0.72 & 0.77 & 0.77 & 0.42 & 0.43 \\
\hline
\end{tabular}

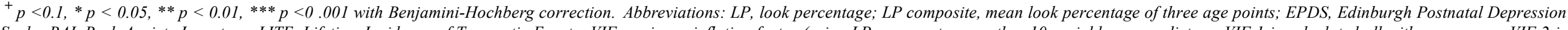

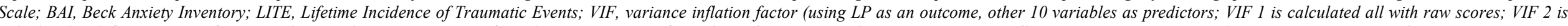

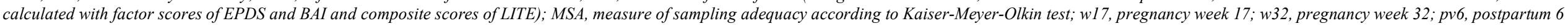
weeks; pm6, postpartum 6 months; IP, interpersonal events; nIP, non-interpersonal events; NA: not applicable, as LP 6, 10, and 18 months were used as dependent variables. 


\section{Figures}

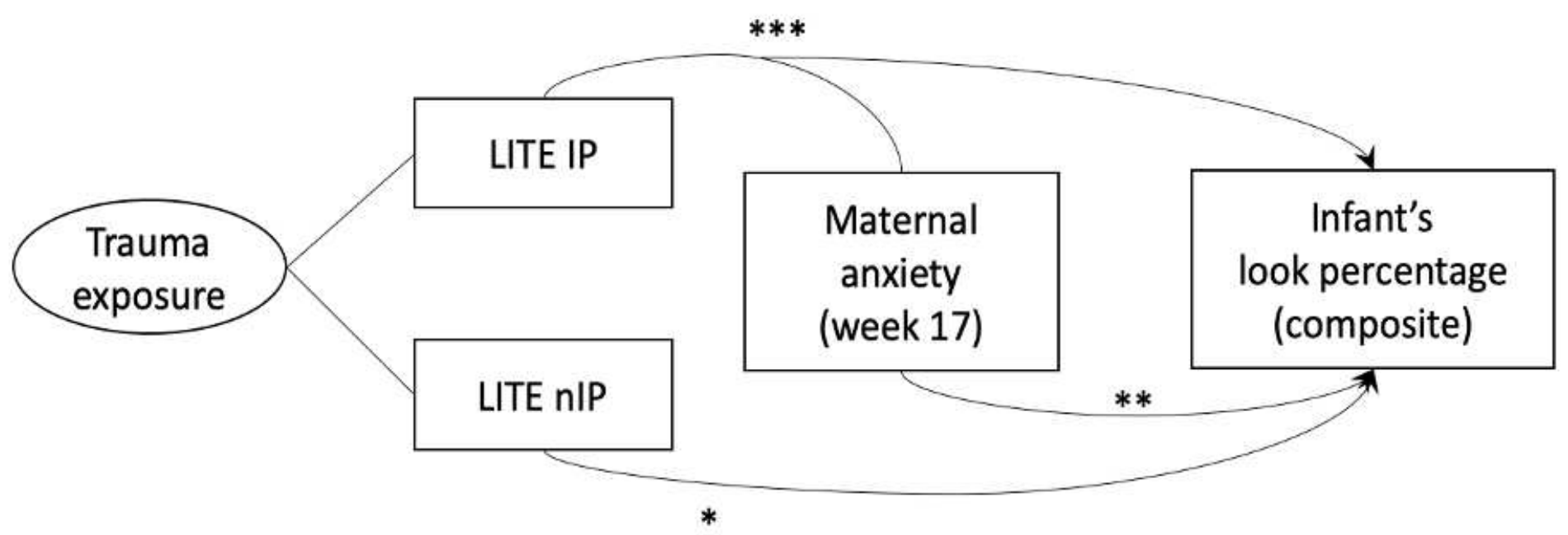

\section{Figure 1}

Illustration of the multivariate linear regression model after adjusting for the sex of the infant, mother's education level, smoking history, and the maternal age at birth. Non-interpersonal traumatic experiences in mother's childhood and maternal anxiety in early pregnancy had a direct impact on the infants' look percentage $\mathrm{Co}=0.014$ and 0.006 , respectively). When anxiety at week 17 of pregnancy interacts with interpersonal traumatic exposure in childhood, the negative impact on the infants' look percentage is highly significant $(p<0.001)$. LITE, Lifetime Incidence of Traumatic Events; IP, interpersonal events; nIP, non-interpersonal events. 


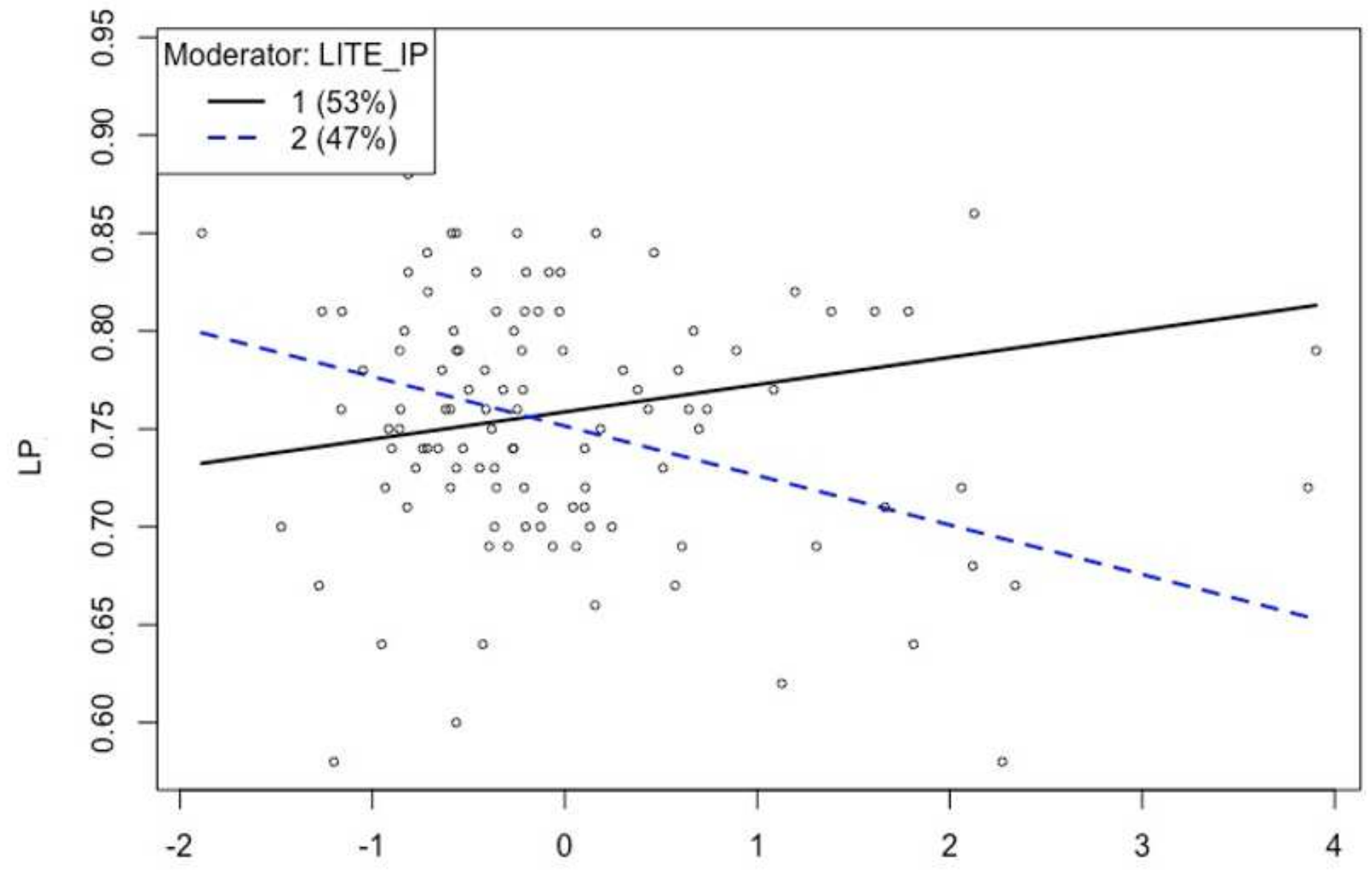

BAl week 17

Figure 2

The relationship between maternal anxiety (Beck Anxiety Inventory at antenatal 17 weeks, BAI week 17) and infants' attention, look percentage (LP), is moderated by the level of interpersonal traumatic events (IP) in childhood measured by Life Incidence of Traumatic Events (LITE). Level 1 (solid line) represents mothers who exposed to less trauma in childhood compared to those at level 2 (dotted line).

\section{Supplementary Files}

This is a list of supplementary files associated with this preprint. Click to download.

- SupplementaryInformationSP.pdf 